\title{
Farm Vehicle Crashes on U.S. Public Roads: A Review Paper
}

\author{
Kasra Karimi, Ardeshir Faghri* \\ Department of Civil and Environmental Engineering, University of Delaware, Newark, USA \\ Email: ^faghri@udel.edu
}

How to cite this paper: Karimi, K. and Faghri, A. (2021) Farm Vehicle Crashes on U.S. Public Roads: A Review Paper. Open Journal of Safety Science and Technology, 11, 34-54.

https://doi.org/10.4236/ojsst.2021.112004

Received: May 10, 2021

Accepted: June 13, 2021

Published: June 16, 2021

Copyright (c) 2021 by author(s) and Scientific Research Publishing Inc. This work is licensed under the Creative Commons Attribution International License (CC BY 4.0).

http://creativecommons.org/licenses/by/4.0/

\begin{abstract}
Farm vehicles (FVs) are not primarily designed for road transportation purposes, but often need to share the roads with other motorists. The interference of these large, slow-moving vehicles with the regular traffic can lead to hazardous situations and cause severe crashes. Farm Vehicle Crashes (FVCs) are rare compared to the total number of road crashes, and hence, have been neglected by many. This has been reflected in various aspects including data collection, education, legislation, and prevention. The number of FVCs in the U.S. has been steady over the last decade. This paper conducts a literature review to put forth a better understanding of this safety issue from a transportation standpoint. The main goal of this study is to identify the characteristics of FVCs, the unique contributing factors in FVCs, and possible strategies to mitigate the issues involved. It appears that despite their lower frequency, the rate of severe injuries and fatalities in FVCs is significantly higher than the average for all crashes. The percentage of fatal crashes in FVCs can be nearly five times higher than average for all road crashes. Further, it is estimated that FVs are overrepresented in road crashes considering their low exposure on the roads. The crash contributing factors including timedependent variables, weather and road surface conditions, location, road classification, manner of collision, and driver's characteristics are discussed based on the result of multiple studies in different states of the U.S. Several unique characteristics of FVCs distinct them from non-farm vehicle crashes which can result from the characteristics of FVs, rural roads, and the nature of farming tasks. Improvements in lighting and marking, equipping farm vehicles with Rollover Protective Structure (ROPS) and seatbelts, educating the public and farmers, and roadway improvements are recommended as potential safety improvement strategies for mitigating the frequency and severity of FVCs.
\end{abstract}

\section{Keywords}

Traffic Safety, Farm Vehicles, Rural Road Safety, Road Crashes, 
Agricultural Vehicles

\section{Introduction}

The agriculture industry now depends on farm machinery and equipment more than at any time in the past. According to the 2017 Census of Agriculture [1], nearly 4.5 million farm vehicles (FVs) operate in the U.S. farmlands, consisting of tractors (91\%), grain and bean combines (7\%), cotton pickers, and strippers $(0.5 \%)$, forage harvesters (1.5\%), and other self-propelled farming equipment. Despite many advantages of modern agricultural machinery, FVs are hazardous by nature and are known to be a leading cause of death among farmers [2]. The unfortunate incidents involving FVs are not only limited to farmlands and many of them occur on roadways. These vehicles are not primarily designed to serve as a means of transportation and their main purpose is to accomplish agricultural tasks [3]. However, farmers and ranchers often need to drive these vehicles on public roads to travel from one field to another to transport equipment, goods, livestock, and labor between fields and markets [4]. FVs are usually wider, heavier, and slower than typical road vehicles, and when traveling on public roads can impact the transportation network by deteriorating the pavement, creating congestion, and more importantly, posing safety hazards on the road. Similar to a study by Maryland Soybean Board [5], for simplicity purposes, road crashes involving agricultural/farming vehicles and equipment are referred to as Farm Vehicle Crashes (FVCs) throughout the rest of this paper.

The majority of FVCs are either collisions with other vehicles or single-vehicle crashes where the FV runs off-roads and rolls over or hits a fixed object [6]. FVCs are considered rare compared to crashes involving typical vehicles such as passenger cars, trucks, and motorcycles [7] [8] [9] [10]. This has led many to underestimate the importance of this issue and neglect this crash category in various aspects including data collection, education, legislation, and prevention [7]. However, it can be argued that the FVs' level of exposure on public roads is significantly lower than the average of all vehicles, and the severity of FVCs is considerably higher [11] [12] [13] [14]. The number of FVs is only a fraction of all vehicles, and it is claimed that these vehicles spend less than $5 \%$ of their operating time on public roads, yet they are overrepresented in road crashes considering their low miles traveled [3] [6]. In North Carolina, it was estimated that the number of crashes per Vehicle Miles Traveled (VMT) for FVs was 1.3 to 2.3 times the rate for all vehicles [9].

Many transportation agencies are now adopting the goals of the Vision Zero plan [15] and The Road to Zero [16] which aim to prevent fatalities and serious injuries by prioritizing the crashes with higher severity. This highlights the importance of acknowledging FVCs as a severe crash category and taking appropriate preventative measures to mitigate them. Providing safe means of transport 
under the concept of equity for all road users has been a hot topic in the past few years. Much attention has been focused on developing complete streets in urban environments while rural roads should also accommodate safe transportation for all users including farmers and ranchers [8].

This study provides a review of the existing literature and aims to address the cause and extent of the safety issues associated with the transportation of FVs on public roads and present possible strategies that can improve the safety of FV drivers and other motorists who share the roads with them. For that purpose, the following objectives are defined:

- Presenting the statistics on FVCs to assess the extent of the problem;

- Reviewing historic crash data analyses to identify the most common contributing factors in FVCs;

- Identifying the unique characteristics of FVs that can potentially contribute to the high severity of FVCs;

- Discussing the possible preventative measures that can mitigate the frequency and severity of FVCs.

The paper is outlined as follows: Section 1 presents the Introduction. Section 2 summarizes the Farm Vehicle Crash (FVC) statistics in the United States and some data from throughout the world. Sections 3 and 4 give a detailed picture of what makes FVCs unique and different from other more common crashes. Section 5, Safety Improvement Strategies, presents methods that can potentially curtail the number and severity of FVCs. Concluding remarks are presented in Section 6 of the article.

\section{Farm Vehicle Crashes (FVCs) Statistics}

Most studies around the world unanimously agreed upon the absence of a reliable database regarding FVCs [17] [18] [19]. This can result from a lack of uniform terminology and data collection methods. Different sources have used various terms to describe FVs, e.g. some of the common terms are "farm equipment" [4] [20], "agricultural machinery" [3], "agricultural vehicles" [13], and "agricultural equipment" [8]. This difference can also be seen among the definitions where some sources included farm trucks and others did not [7]. Further, some crash reporting systems may have a separate category for FVs, while others include them in the "other vehicles" category [21]. This argument even holds within the U.S. where the definitions, laws, and accident reporting systems sometimes vary among different states [7]. Nevertheless, the Fatality Analysis Reporting System (FARS), indicates that FVCs have $t$ an average of 87 lives annually between 2010 to 2018 in the U.S. As it is shown in Figure 1 the number of fatal FVCs has remained relatively steady in this period. This steady trend was also seen in the annual number of FVCs in Iowa for over three decades [22].

In the absence of a comprehensive national database for FVCs, the frequency of these crashes was extracted from multiple publications that reported the occurrence of FVCs at a state level presents this result to put forth a better idea of the prevalence of these crashes. As can be seen in Table 1 the table, this topic is 


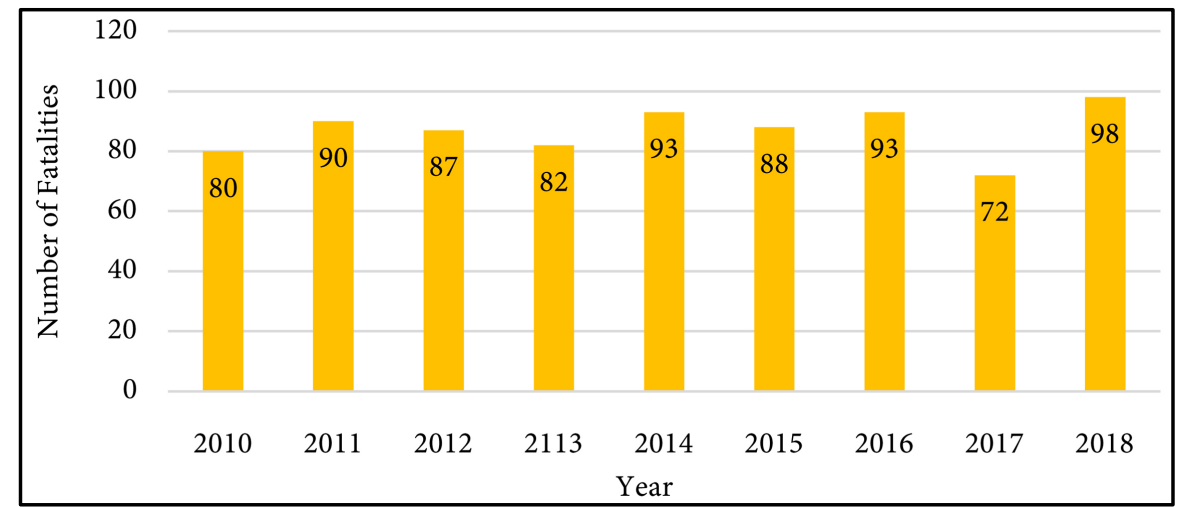

Figure 1. The number of fatal crashes in the U.S involving FVs based on the FARS database [23].

Table 1. FVCs statistics in different countries and the U.S. states.

\begin{tabular}{cccc}
\hline Study location & Reference & Study period & Average Annual Crashes \\
\hline Delaware & {$[24]$} & $2005-2020$ & 13.7 \\
Illinois & {$[8]$} & $2005-2008$ & 193 \\
Iowa & {$[6]$} & $1949-1959$ & $280.6(\mathrm{~T})$ \\
Iowa & {$[17]$} & $1949-1966$ & $289(\mathrm{~T})$ \\
Iowa & {$[25]$} & $2004-2006$ & 199 \\
Iowa & {$[8]$} & $2005-2008$ & 190 \\
Iowa & {$[4]$} & $2005-2011$ & 228 \\
Iowa & {$[26]$} & $2004-2014$ & 191 \\
Kansas & {$[8]$} & $2005-2008$ & 110.2 \\
Maryland & {$[5]$} & $2015-2008$ & 58.5 \\
Minnesota & {$[8]$} & $2005-2008$ & 137.5 \\
Missouri & {$[8]$} & $2005-2008$ & 165 \\
Nebraska & {$[8]$} & $2005-2008$ & 79.5 \\
New York & {$[13]$} & $2010-2012$ & 67.6 \\
North Carolina & {$[27]$} & $1995-1999$ & 299 \\
North Carolina & {$[22]$} & $1966-1999$ & 34.2 \\
North Dakota & {$[8]$} & $2005-2008$ & 200 \\
Ohio & {$[3]$} & $1989-1992$ & 170.2 \\
South Dakota & {$[8]$} & $2005-2008$ & $2005-2008$ \\
Wisconsin & {$[8]$} & & 29.2 \\
\hline
\end{tabular}

T. Only tractor-related crashes were reported.

relatively well studied in some Midwestern states, particularly in Iowa. The average annual number of FVCs in different states approximately varies from 14 to 300 crashes, and Iowa, North Carolina, and Ohio have the highest number of FVCs. 


\section{Characteristics of FVCs}

This section aims to identify the role of different variables to find out when, where, to whom, how, and how serious FVCs commonly happen. Those studies that analyzed FVCs are reviewed and the most common risk factors in FVCs are discussed in the following.

\subsection{Time-Dependent Variables}

The presence of FVs on the roads is affected by the seasonal nature of farming activities [3]. Several studies found that the majority of the FVCs occurred in the fall, and October was reported to be the peak month [3] [5] [6] [20] [25]. A study of the FVCs in Midwestern states [8] defines the farming seasons as winter (Jan-Mar), planting (Apr-May), growing (Jun-Aug), and harvest (Sept-Dec). This study indicated that the harvesting season accounted for nearly $40 \%$ of the crashes. Another pattern was reported in North Carolina [27] and Delaware [24] which consisted of two peaks, where a greater one appeared between April and July and a smaller one between August to November. All the aforementioned studies reported that the frequency of the crashes was the lowest during winter.

The majority of the FVCs happen throughout the workdays of the week, and weekends (Sundays, in particular), have the lowest rate [20] [22]. An early study in Iowa 1961 [6] reported two peak hours for FVCs, one in the late morning (10-11 AM) and another in mid-afternoon (4-5 PM). Several other studies reported that the majority of crashes happened between 2-6 PM and then dropped down after 7 PM [3] [20] [22] [27]. In Delaware, it was observed that the distribution of the FVCs throughout the day followed a symmetric normal distribution where the peak for all FVCs occurred at $12 \mathrm{PM}$. However, when factoring in the injury rate, those crashes that happened between 12-8 PM had a higher severity [24]. In comparison with all-vehicle crashes, a smaller portion of FVCs occurred at late hours which is predictable since farmers usually stop working after sunset [22].

\subsection{Location and Road Classification}

It can be expected that most FVCs occur on rural roads which are the primary platform for the operation of farm vehicles. An analysis of the national FARS data from 1988 to 1993 showed rural roads account for 94\% of fatal FVCs [19]. A study in North Carolina [27] showed that nearly half of all FVCs occurred on secondary routes. However, a later study in North Carolina [22] claimed that primary highways represent more crashes per mile. This study also showed that two-way two-lane roads account for over $93 \%$ of the FVCs. In Iowa, $41 \%$ of the FVCs occurred on county highways and 26\% on US/state highways [20]. A 2016 study in Iowa [4], reported that $79 \%$ of the accidents happened on roads with a speed limit of $50-60 \mathrm{mph}$, and $30 \%$ of the crashes occurred on unpaved surfaces. Although local routes and the routes connecting farms to markets together accounted for $73 \%$ of the FVCs, state routes had a higher probability of a crash 
occurrence. The study of FVCs in the Midwestern states [8], showed that nearly one-third (30.2\%) of FVCs occurred in urban zip codes and the rest in rural zip codes. In Maryland, it was found that nearly $75 \%$ of the FVCs occurred on two-way roads [5]. It was also indicated that the highest number of crashes took place on the state highways followed by the county roads.

\subsection{Weather and Road Surface Conditions}

A study in Iowa [25] reported that $77.4 \%$ of the FVCs happened on a dry surface, while only $8.9 \%$ of crashes happened on a wet surface. The findings of several other studies also indicate that the majority of FVCs occurred on a dry surface and under a clear weather condition [5] [13] [19] [20] [24]. This might be due to the fact that farmers are more likely to do farming tasks under this condition. The Iowa study [25] also found crashes on a dry surface were more likely to result in injuries. The author potentially justifies this observation by the difference in driving behavior and assuming drivers take a higher level of accepted risk under clear weather.

\subsection{Driver's Characteristics}

Sex and age were the two of the main characteristics of the driver that was discussed by most studies. The share of male FV drivers of the farm vehicle was reported higher than $90 \%$ [20] [22] [25] which is not surprising regarding the fact that farming, in general, is a males dominant industry. A 1996 study [19] compared the age groups of the driver of the FVs with the driver of the non-farm vehicles who were involved in FVCs. It was found that the percentage of drivers in the older ( $>45$ years old) and younger $(<15$ years old) age groups were higher for the drivers of the FV. A similar result was reported in Iowa [20]. The percentage of the FV drivers older than 45 years was 1.3 times the same age group for the non-farm vehicle drivers. A Swedish study [28] found that those in the age group of 25 - 55 comprised the majority of the drivers involved in FVCs, however, those in the younger and older age groups were more likely to be killed or injured. This observation complies with the findings of [25] and [20]. The agerelated decline in vision and driving abilities can increase the perception-reaction time for older drivers and increase the likelihood of being involved in a crash [28]. The lower physical strength for both older ( $>45$ years old) and younger $(<15$ years old) age groups can make them more susceptible to injuries. The 2007 Iowa study [20] indicated that farm vehicle drivers under 15 years old were 2.6 times more likely to be injured compared to the 26 - 65 age group. A study in North Carolina [29] claimed that non-family members and non-English speakers FV drivers were at a higher risk of being involved in a crash.

\subsection{Contributing Circumstances}

Most crashes are caused due to a series of events and human actions and for the majority of the cases, it is difficult to identify a single reason as a cause of a 
crash. However, most crash reports contain certain drivers' actions as leading causes of the crash that were identified by police officers. The study of FVCs in North Carolina [22] showed the FV driver was at fault at 35\% of the crashes while the drivers of the non-farm vehicle were in charge in $42 \%$ of the crashes. Failure to yield right-of-way, exceeding the centerline, obstructed vision, and improper or no signaling as the most common violations by the FV driver, while speeding and improper passing were two of the most common violation committed by the other vehicles' driver [20] [22] [25].

\subsection{Manner of Collision}

Regarding FV collisions with other vehicles, the most common manners of the collision were rear-end, sideswipe-meeting, sideswipe-passing, and angle collisions [3] [22] [25]. Rear-end crashes comprise nearly $25 \%$ of the FVCs and in the majority of the cases, the FV was hit from behind [8] [20] [22] [24] [25]. The share of fatal rear-end collision was found to be 9 times higher for FVCs compared to all other vehicle crashes [19]. A large portion of rear-end crashes occurred during the night, dawn, or dusk [3] [19]. Angle collision was another common type in FVCs which in most cases occurred when the driver of the other vehicle attempted to overtake a FV that is making a left-turn [20] [22]. The share of head-on crashes in most studies was between 3 to 7 percent [3] [5] [8], however, it happens to be the most severe collision. The non-farm vehicle driver was reported to experience injury or fatality in nearly $60 \%$ of head-on FVCs [20].

Rollover is a common type of single-vehicle crash that is known to be one of the leading causes of death among farmers that account for approximately 130 fatalities each year in the U.S. [2] [30]. Rollover (roll-over) or overturn refers to a situation when a vehicle tips to the side, forward, or backward. This incident can be initiated by another vehicle or when driving over a soft shoulder, a steep slope, driving too fast through a sharp turn, when rear wheels suddenly receive extra power, and finally when pulling a load that is not properly hitched to the tractor can be some of the more common causes of rollover [31] [32] [33] [34]. When the farm vehicle rolls over there is a high risk of falling out for the FV driver who is not restrained by a seat belt. The share of rollovers that resulted in a fatality is 2.3 times higher for fatal FVCs compared to all other vehicle crashes [19]. A study in 1961 estimated the fatality rate for rollover crashes to be between $41 \%$ and $55 \%$ [6].

\section{Unique Contributing Factors in FVCs}

Many factors can contribute to the occurrence of FVCs, some of which might be similar to non-farm vehicle crashes, but certain unique features make FVCs distinct from a typical road crash. These distinctive features originate from the characteristics of FVs, rural roads, and farming tasks. Identifying and perceiving these characteristics is necessary for establishing effective countermeasures. 


\subsection{Vehicle-Related Factors}

\subsubsection{Large Dimensions}

As the farming industry has trended towards larger-scale plantations in the past few decades, FVs have also become larger and heavier. The width of the FV in some cases even exceeds the width of a typical 12-foot highway lane [4]. In addition to the size of the vehicle itself, vehicles attached equipment such as pluggers and scrapers can often exceed the overall width of the vehicle. For instance, the width of KUHN Krause 4400 soil finishers and packers range from 12.4 to 19 feet [35]. Similarly, towing parts such as grain carts and trailers can significantly increase the overall length of the vehicle. The large dimensions make the maneuverability of the vehicle more challenging, increase the driver's blind spots, block other motorists' field of view, and increase the chance of collision for oncoming and passing vehicles.

When crossing the road section or making a left-turn, the excessive length of FVs plus the towing parts and equipment in combination with their slow speed could result in blocking the road longer than a typical vehicle. This is one of the reasons for the high rate of left-turn collisions involving FVs. Similarly, the excessive width of the vehicle exposes a larger potential impact surface which increases the chance of rear-end, sideswipes, and head-on collisions. Such hazards can be aggravated when the vehicle travels on narrow two-lane rural roads.

\subsubsection{Difference in Speeds}

Most FVs are considered Slow-Moving Vehicles (SMVs) which travel at the maximum speed of $25 \mathrm{mph}$ [22]. Providing sufficient torque is much more important for farm work than speed. Moreover, towing heavy equipment will slow these vehicles down even more. The difference in speed between the slowmoving farm vehicle and the regular traffic can cause safety hazards and result in a crash. The increase in relative speed between two colliding vehicles has a direct relationship with the magnitude of the impact energy and therefore the severity of the collision. As it was discussed in Section 3.6 of this paper, rear-end collisions are the most common manner of collision among FVCs. A common scenario is when the driver of a fast-moving vehicle approaches the farm vehicle from behind and either miscalculates their speed or fails to respond quickly and causes a rear-end collision [36]. Additionally, the blind curves and insufficient sight distance in many rural roads can aggravate this issue.

\subsubsection{Design Factor}

FVs are not primarily designed to travel on roads; instead, they were meant to operate in the muddy and harsh environment of farming fields. While safety is a top priority in designing passenger cars, trucks, and other typical road vehicles, this is not the case for FVs. Modern vehicles are equipped with multiple safety features such as seatbelts, an Anti-lock Braking System (ABS), airbags, and Advanced Driver Assistance Systems (ADAS) to minimize the risk of a crash and its severity. Engineers also try to design deformable body parts that absorb 
the majority of the kinetic energy from a potential crash. However, in the design process of FVs, safety does not receive the same attention. Although modern FVs are equipped with seatbelt and ROPS, most of the safety regulations do not apply to them which can contribute to the higher rate of severe injuries and fatalities in FVCs.

Lighting and marking on FVs and equipment are other important features that haven't received proper attention in the design process until very recently. Headlamps and rear lights in passenger cars and trucks are usually placed in a manner that properly indicates the width of the vehicle. However, for many of the FVs, the wheels or other parts of their attached equipment exceed the actual width of the vehicle and there is no proper lighting device that alerts other motorists to easily identify the outer edges of the vehicle.

As it was discussed earlier, the percentage of rollover among FVs is significantly higher than it is for non-farm vehicles. One of the features that contribute to this issue is the lack of a suspension system [33]. Tractors, in particular, are not equipped with a suspension system since, in farming tasks such as plowing, suspension springs can absorb part of the energy and reduce their efficiency. However, the lack of a suspension system when traveling on uneven surfaces increases the likelihood of a rollover.

\subsubsection{Loud Engine}

The noisy and loud engine on FVs is another factor that can affect a driver's performance on the roads. It can be challenging for the FV driver to hear the sound of an approaching vehicle or a vehicle honking in a hazardous situation. In combination with low visibility, this can reduce the drivers' ability to respond to a hazard quickly.

\subsubsection{Outdated Equipment}

It is estimated that the average age of a tractor in the U.S. is over 25 years old [37]. Older vehicles usually are equipped with fewer safety features and are more prone to have nonfunctional systems such as broken lights or faded markings [36]. More effective brake systems, enclosed cabins, ROPS, and seatbelts are some of the effective features for improving the safety of the driver that are installed on newer models by the manufacturers but are missing on many older FVs. Particularly, ROPS is more likely to be missing on those tractors manufactured before 1985 [37] [38]. An inspection of 91 farm tractors in Kentucky showed an average age of 23.6 years for these vehicles with a standard deviation of 20.9 years which indicates a wide range of variability [39].

A 2010 study in Iowa [25] found that the average age of FVs involved in the crashes was 16.5 , with a standard deviation of 15.7 years. $13 \%$ of the FVs were older than 29 years and were found to be at a higher risk of causing fatal or major injury crashes compared to the newer vehicle.

\subsubsection{Variety of Attachments}

FVs and tractors, in particular, are designed to perform various farming tasks 
such as plowing, tilling, and planting. Each task requires a different set of equipment that will be attached to the front or rear of the vehicle. Some of the common attachments are loader buckets, blades, mowers, rotary cutters, lawn pluggers, scrapers, forks, rakes, and towed parts like grain carts and trailers. Installation and maintenance of lighting devices and reflectors on some of these attachments can be challenging. Due to the essence of the farming tasks, such as working in some harsh and muddy environments, lights and reflectors cannot be permanently mounted on the attachments because they are often become broken or fade quickly.

\subsubsection{Improper Transport and Towing Techniques}

FVs are commonly used for transporting farming equipment and towing implements such as grain carts and liquid tanks. Failure to securely attach equipment to the vehicle or on the transport trailers can cause hazardous situations [36]. Towing equipment too fast when turning is a common mistake that can result in a rollover. This can particularly happen when towing dynamic loads such as liquid tanks. The liquid's movement in the tank changes the center of mass and generates lateral momentum which can potentially tip the vehicle over.

\subsection{Rural Roads-Related Factors}

As it was mentioned in Section 3.2 over two-third of FVCs occur in rural areas. Further, one study reported that rural roads account for $94 \%$ of fatal FVCs in the U.S. [19]. Two-lane rural roads are considered to be one of the most common routes for farm vehicle transportation. Despite the lower traffic volume on these roads, rural road crashes are more likely to be severe [40] [41]. They account for nearly half of the national roadway fatalities, while they only comprise about $30 \%$ of national vehicle miles traveled [42]. According to the FARS database, two-lane roads account for $62 \%$ of the fatalities [23]. The National Highway Transportation Safety Administration (NHTSA) reports that in 2017, the fatality rate per 100 million vehicle miles traveled was 2.1 times higher in rural areas than in urban areas. Certain types of severe crashes disproportionately take place on rural roads. About $80 \%$ of fatalities due to run-off-the-road (ROR) crashes occurred on rural roadways, two-lane highways account for $90 \%$ of those crashes [43]. Further, 75\% of head-on collisions occur on undivided two-lane roads [44].

Following are some of the common general safety issues in rural roads that can potentially contribute to the higher risk of severe crashes including FVCs.

\subsubsection{Lack of Safety Features}

In the design process of roadways, safety requirements vary with respect to the road type and traffic volume. Rural and country roads usually have lower traffic volume and therefore fewer safety requirements. Paved shoulders, lighting, marking, signalized intersections, guard rails, rumble strips, and median barriers are some of the most important examples of safety features that may not be provided on many of the low-volume rural roads. Some of these features can play a 
crucial role in preventing crashes. For instance, one of the major reasons for the high rate of head-on collisions on two-lane rural roads is the lack of a median or a barrier that separates the traffic in opposite directions. Another important feature is lighting. A study in Minnesota [45] showed that installation of lighting at isolated rural intersections can reduce the number of crashes during dark hours by $32 \%$ on average and decrease their severity by $17 \%$.

\subsubsection{Blind Curves}

Many low-volume rural roads are laid on the natural topography of the land, in order to minimize the cost of the construction (e.g. avoiding excavation). Consequently, sharp corners and steep hills can be commonly seen on these roads, especially in mountain areas. Further, natural vegetation, cornfields, and other natural obstacles can also create blind spots and obstruct drivers' visibility and block their view of other vehicles on the roads.

\subsubsection{Poor Pavement Conditions}

It's more likely on rural roads that the pavement doesn't receive adequate maintenance. It is reported that $13 \%$ percent of the nation's rural roads have poor pavements conditions [46]. Driving over uneven surfaces, potholes, ditches, trenches, and wash-outs can cause the drivers to lose control of the vehicle, run off the road, or collide with another vehicle when trying to avoid those obstacles [36].

\subsubsection{Narrow Roads and Bridges}

Fewer and narrower lanes in rural roads and bridges can increase the risk of a crash especially considering the large dimensions of the FVs. Two-lane roads comprise $86 \%$ of the nation's rural non-freeway arterial roads, further, the width of $23 \%$ of rural collector and arterial is 10 feet or less [46]. The width of FVs usually ranges between 10 and 25 feet, which is much wider than the standard 12-foot-wide lane [4]. A study in Iowa reported that increasing the width of the road by 5 feet can decrease the risk of FVCs by $10 \%$ [4].

\subsubsection{Unmarked Driveways}

Many of the farm access and driveways are not properly marked in rural roads and might remain hidden to a motorist unfamiliar with the road. Therefore, the drivers of the non-farm vehicles remain unprepared when encountering a FV entering or exiting the main road which can lead to a collision.

\subsubsection{The Element of Surprise: Wildlife and Farm Animals}

Encountering animals on the roads is a major risk factor. Federal Highway Administration (FHWA) reports that there is an estimated one to two million collisions between cars and large animals every year in the U.S. Rural roads account for 74 to 94 percent of these crashes [47].

\subsubsection{Lack of Law Enforcement}

The supervision of the police and law enforcement devices like speed cameras 
are lower in rural roads with low traffic volume compared to arterials [20]. This opens up the possibilities of unrulier behavior (particularly speeding) on the drivers' part, as there are fewer constraints to hold them back [40].

\subsubsection{Post-Crash Care}

The EMS response time is another factor that can impact the consequences of crashes by increasing the likelihood of fatality or major injuries. The average time from the occurrence of the crash to arrival at the hospital for nearly $40 \%$ of the crashes in rural areas is between 1 to 2 hours, while in urban areas this is only less than $10 \%$ of the cases [10]. Another contributing factor that can increase the EMS response time is the lower chance of crash witnesses on rural roads who can make a phone call and request emergency service.

\subsection{Farming-Related Factors}

\subsubsection{Long Working Hours}

Farming is a time-sensitive occupation and farmers have to compete against the clock to complete many of the field operations. Farmers work hard throughout the year and during the planting and harvesting seasons, they often work sevenday with daily hours that can sometimes reach up to sixteen. The stress and fatigue from intense workdays in addition to other distractions can increase the possibility of mistakes and therefore accidents [48].

\subsubsection{More Vehicles}

Farming is now reliant on modern machinery more than ever, and there are various types of equipment for each farming task, which means the number of FVs and equipment and consequently, the possibility of them being on the roads is higher than before [48].

\subsubsection{Urbanization of Farmlands}

Over the last few decades, the growth of the population and people escaping from populated city environments has expanded the urban areas towards suburbs and rural areas. Many lands have changed their land-use from agriculture to residential while being surrounded by other farmlands which have increased the traffic conflicts between FVs and other motorists [7] [38].

\subsubsection{A Public Less Familiar with FVs}

In the past, when the urban and rural traffic had less interference, the drivers who encountered FVs were usually locals who were familiar with farming operations and were more prepared "when" and "where" to expect FVs and how to react when sharing the road with them. However, as cities have spread into farming areas and more people have moved out of cities to rural areas as a consequence of remote working opportunities, many drivers are unaccustomed to FVs on the roads [48]. A survey in North Carolina [49] showed that most farmers believe that driving their farm vehicle is now more dangerous than in the past. 


\subsubsection{Unskilled Operators}

Large and complicated FVs require skillful, and well-trained operators [36]. However, the labor needed for farming varies throughout the year and during harvesting and planting seasons farmers often need to hire temporary employees who do not necessarily have sufficient experience in driving FVs. These inexperienced drivers are more likely to be involved in road crashes.

\subsubsection{Extra Riders}

FVs often are used for transporting labor between fields, while these vehicles are not designed for carrying passengers and do not offer any safety features for the extra riders. Extra passengers can be at a higher risk of being injured in a crash or can even fall off the vehicle and being run over by the FV or other vehicles [36].

\subsubsection{Children Workers}

Most people who work on farms live there as well and children usually get involved in this industrial setting to some level. It was estimated in 2014 that 893,000 youth under 20 years old reside on farms [30]. Many start operating FVs at a young age before having any valid driving/operating license [34]. Operating FVs requires experienced and skilled operators and under-aged drivers can increase the risk of a crash.

\subsubsection{Aged Workers}

Farmers do not have a particular retirement age. Working at older ages is very common in agriculture. A 1992 study estimated that the average age of U.S. farm operators to be 52 , and $21 \%$ of them being 65 or older [34]. Older age groups are at a higher risk of being involved in accidents due to decreases in their decision-making abilities and physical characteristics. Moreover, people in the age group of 65 and higher, are two to three times more prone to be severely injured compared to other age groups [34].

\section{Safety Improvement Strategies}

Several strategies and practices have been developed to reduce the occurrence of FVCs and their severity. Most preventive strategies target one of the main elements of a crash: the roadway, the vehicle, and the driver. Post-crash care is another element of a Safe Systems Approach [50] that can also play a crucial role in reducing the severity of the consequences. The followings are some of the main strategies that can be implemented for reducing the risk of FVCs:

> Improvements in road conditions and safety features, particularly for undivided two-way two-lane rural roads.

$>$ Improvements in the manufacturing of the FVs and equipment regarding their safety features, not only to protect the FV driver but also considering the safety of other motorists.

$>$ Minimizing the interference of farm vehicles and other motorists by encouraging farmers to use alternative routes if possible.

Educating and training farmers on the safe operation of their vehicles on 
public roads.

Educating the public on sharing the road with farm vehicles.

Development of effective regulations for the operation of FVs on public roads to minimize the risk exposure.

$>$ Development of effective law enforcement methods and speed management techniques to reduce speeding in low-volume rural roads with high FV traffic.

$>$ Development of a unified crash reporting system that captures accurate and information of FVCs and results in establishing a comprehensive database.

The most effective safety improvement strategy is a comprehensive one that utilizes all these approaches. However, discussing all these strategies is out of the scope of this paper, and in the following, only a few countermeasures are recommended based on the results from the crash analysis section. As it was discussed in Sections 3 and 4, blind curves, inaccurate perception of other drivers of FVs' speed, insufficient road width, and inadequate safety features were some of the highlighted contributing risk factors in FVCs. Therefore, the following measures are suggested in order to mitigate these issues.

\subsection{Roadway Safety Improvements}

\subsubsection{Making Passing Safer}

The width of the road is one of the most important contributing features for FVCs. The insufficient width particularly becomes an issue in two-lane two-way rural roads when other motorists try to overtake the slow-moving farm vehicle. Large farm vehicles often occupy the whole width of the lane or the majority of it, which not only increases the risk of read end and sideswipe collisions but also blocks other motorist vision and increases the risk of them being involved in a head-on collision while passing.

Extending the width of the road can be done either by adding another lane, widening the existing lanes, or adding a shoulder. This can allow farm vehicles to have a safer space for traveling and maneuver while also improving the sight distance for other motorists and provide them better visibility during passing. However, construction of either option for the whole length of a segment can be very costly.

A less expensive alternative can be adding passing bays (turnouts) along those segments with insufficient width and high farm vehicles' traffic volume. This bypass mechanism can allow the farm vehicles to pull over and let the through traffic pass which reduces the chance of unsafe passing as well as reducing the congestion. A passing bay lane can be attached to the through lane or be separated by a barrier. A wedge-shaped barrier (as shown in Figure 2) can guide the farm vehicle driver through a more perpendicular merging angle which can provide the driver with a better field of view of the through traffic.

\subsubsection{Making Left-Turn Safer}

Angle collision is one of the common types of FVCs, particularly during the 


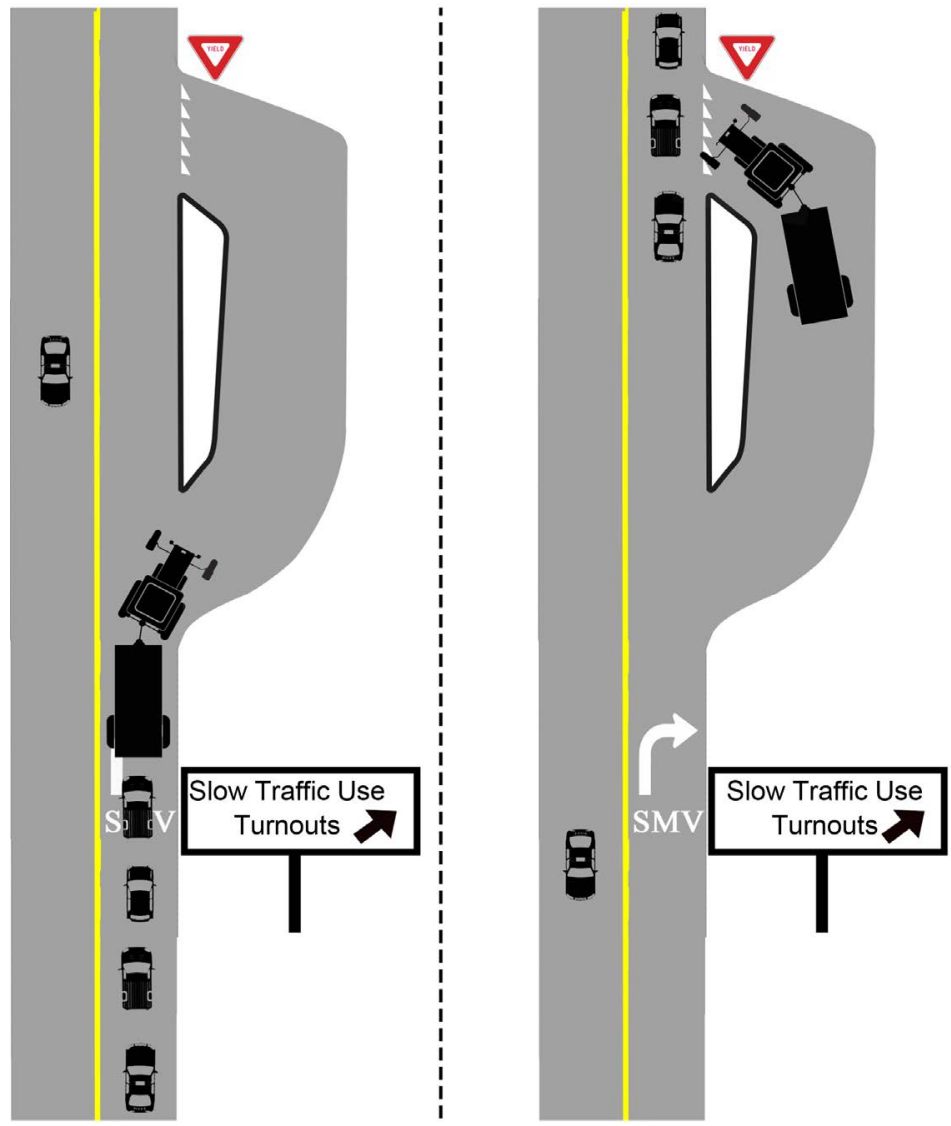

Figure 2. Sketch of a turnout for SMVs alongside two-lane road [51].

left-turn maneuver by the farm vehicle. A farm vehicle trying to turn left on a two-lane two-way road can also lead to a rear-end collision while the farm vehicle is stopped and waiting for the safe gap. Because of their slow speed and excessive length of the vehicle and the towing equipment, farm vehicles need a larger gap for accomplishing a left than a regular vehicle. Two countermeasures are introduced in Figure 3 which both follow the same concept of widening the road at the left-turn section. Figure 3(A) proposes adding a designated left-turn lane, and Figure 3(B) suggests providing a paved or unpaved passing bay (turnout) at those spots with a high volume of farm vehicles left-turn such as farm driveways. Depending on the physical characteristics of the road and traffic behavior, either alternative can be helpful. Alternative B might be more suitable for situations where vehicles more likely to form a platoon. It allows the platoon to pass with no interference and provides the farm vehicle driver with a better field of view.

\subsection{Farm Vehicle Safety Improvements}

\subsubsection{Lighting and Marking}

Proper lighting and marking on a vehicle help other motorists to be aware of its presence and dimensions. This matter becomes more crucial when it comes to farm vehicles and equipment. These vehicles are usually much wider than regular 

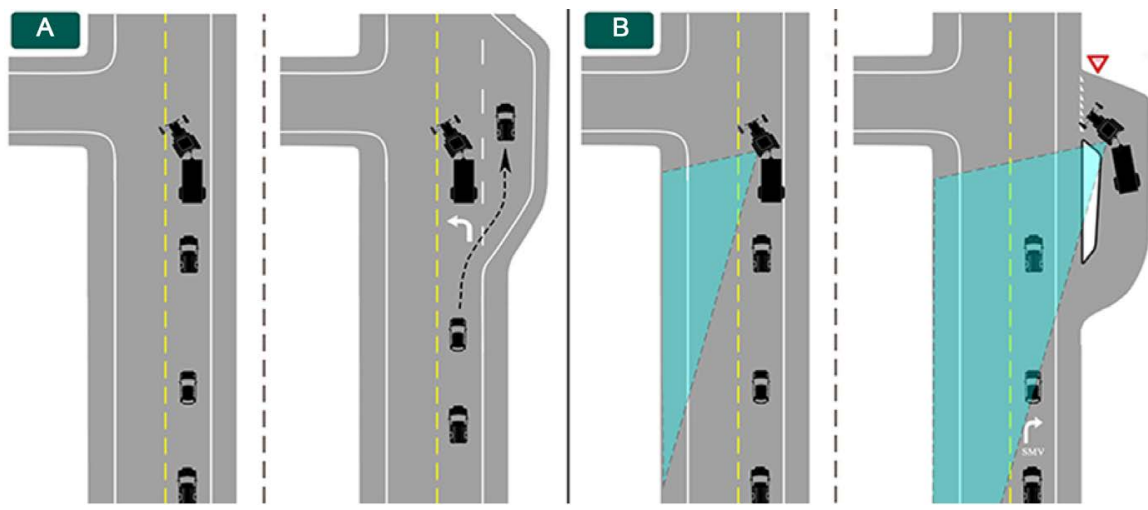

Figure 3. (A) Adding a designated left-turn lane. (B) Adding a passing bay at a high-risk left-turn location [22].

road vehicles and often travel with various attachments that exceed the dimensions of the vehicle. This can make it challenging for other motorists to locate the farm vehicle's outer edges correctly and maintain a safe distance, especially in the dark.

Another feature that distinguishes farm vehicles from non-farm vehicles is their slow speed which is usually limited to $25 \mathrm{mph}$. The Slow-moving vehicles (SMV) emblem is designed to alert other motorists of this matter so they can safely adjust their speed. The crash history analysis in Delaware showed that farm vehicles were about 4 times more likely to be hit from behind in a dark condition, compared to the daylight situation, which indicates the importance of lighting and marking on the rear of these vehicles. The lighting and marking standards developed by the American Society of Agricultural and Biological Engineers (ASABE) [52] are currently known to be the most effective guidelines. In addition to updating the regulations, effective methods should be developed to inform farmers of the mandatory and volunteering safety improvements related to the operation of their vehicles on public roads.

\subsubsection{Rollover Protective Structure (ROPS)}

ROPS or crush-proof cab are structures that are designed to protect the driver during a rollover incident. A study in 2000 [53] reported that ROPS were only available on about $50 \%$ of the estimated 4.8 million tractors in the U.S. Another study in Kentucky [39] reported a similar observation in 2009 that only half of the tractors were equipped with ROPS. Some manufacturers began to implement a voluntary ROPS standard for tractors built after 1985. However, a significant portion of ROPS was removed from those vehicles by farmers [53]. There is strong evidence that ROPS can significantly reduce the fatalities from rollovers unless the driver does not use the seatbelt. The estimated cost for equipping older tractors with ROPS ranges from approximately $\$ 500,000$ to $\$ 900,000$ per life saved [53]. The National Institute for Occupational Safety and Health (NIOSH) [2] in 2004 predicted that if ROPS requirements were phased in over an 18 years period, 2000 lives could be saved in the U.S. ROPS has proven to be one of the 
most effective advances in protecting farm vehicle drivers in a rollover accident. Mandating the use of ROPS and other safety features for farm vehicles through regulating machinery design and manufacture is one of the most effective ways of minimizing farm tractor accidents [33].

\section{Conclusions}

Certain characteristics of FVs such as slow speed, heavy weight, and large dimensions can pose safety hazards on the roads. Collision with non-farm vehicles and rollovers are two main types of crashes involving FVs that can lead to severe injuries and fatalities for farmers and other motorists on the roads. FVCs comprise only a fraction of total roadway crashes, however, 1) their frequency is disproportionate to the number of farm vehicles and their miles traveled on public roads compared to passenger cars and trucks, 2) the severity of FVCs is much higher than non-farm vehicle crashes. The fatality rate of FVCs is significantly higher than it is for all vehicle crashes, and occupancies of the non-farm vehicle involved in a FVC are at a higher risk of being injured compared to the driver of the FV.

Most FVCs happen during plantation, growing, and harvest seasons and fewer during the winter. The majority of FVCs occur during the daytime, under clear weather, and on a dry surface. The majority of the FV drivers involving in crashes were predominantly male and belonged to the age group of $25-45$. However, the percentage of fatalities and injuries was higher for the younger and older age groups. The most frequent type of collisions involving non-farm vehicles were the rear-end, sideswipe, and angle (left-turn) collisions. Nearly two-thirds of FVC's were reported to occur in rural zones and the majority of collisions took place on non-divided two-lane rural roads with a speed limit of 50 - $60 \mathrm{MPH}$. Multiple studies reported a fatality percentage of $2 \%$ to $4 \%$ and found FVCs to be approximately five times more severe than regular road crashes.

Improvements in lighting and marking, equipping farm vehicles with Rollover Protective Structure (ROPS) and seatbelts, educating the public and farmers, and road improvements are some of the most effective safety improvement strategies for mitigating the frequency and severity of FVCs.

\section{Acknowledgements}

The authors would like to express their gratitude to the Delaware Department of Transportation (DelDOT) and the Delaware Center for Transportation for supporting this project. In particular, all the assistance received from Mr. Scott Neidert who served as the project manager is much appreciated.

\section{Conflicts of Interest}

The authors declare no conflicts of interest regarding the publication of this paper. 


\section{References}

[1] United States Department of Agriculture (2019) 2017 Census of Agriculture: Summary and State Data. Geographic Area Series AC-17-A-51, United States Department of Agriculture, Washington DC.

[2] National Institute for Occupational Safety \& Health (NIOSH) (2004) National Agricultural Tractor Safety Initiative. National Institute for Occupational Safety \& Health, Washington DC.

https://nasdonline.org/static_content/documents/1906/d001837.pdf

[3] Glascock, L.A., Bean, T.L., Wood, R.K., Carpenter, T.G. and Holmes, R.G. (1995) A Summary of Roadway Accidents Involving Agricultural Machinery. Journal of Agricultural Safety and Health, 1, 93-104. https://doi.org/10.13031/2013.19457

[4] Greenan, M., Toussaint, M., Peek-Asa, C., Rohlman, D. and Ramirez, M.R. (2016) The Effects of Roadway Characteristics on Farm Equipment Crashes: A Geographic Information Systems Approach. Injury Epidemiology, 3, Article No. 31. https://doi.org/10.1186/s40621-016-0096-1

[5] Maryland Soybean Board (2019) Maryland Rural Road Safety Study: An Analysis of Farm Vehicle/Farm Equipment-Related Accidents in the State of Maryland. Maryland Soybean Board, Salisbury.

https://www.mdsoy.com/wp-content/uploads/2019/07/MD-Rural-Road-Safety-Stud y.pdf

[6] Wardle, N.J. (1961) Tractors + Traffic = Trouble. Iowa Farm Science, 15, Article No. 4.

https://lib.dr.iastate.edu/cgi/viewcontent.cgi?article=1142\&context=farmscience

[7] The Committee on Agricultural Safety and Health Research and Extension (2009) Agricultural Equipment on Public Roads. National Ag Safety Database.

https://nasdonline.org/2065/d001906/agricultural-equipment-on-public-roads.html

[8] Harland, K.K., Greenan, M. and Ramirez, M. (2014) Not Just a Rural Occurrence: Differences in Agricultural Equipment Crash Characteristics by Rural-Urban Crash Site and Proximity to Town. Accident Analysis \& Prevention, 70, 8-13. https://doi.org/10.1016/j.aap.2014.02.013

[9] Costello, T.M., Schulman, M.D. and Luginbuhl, R.C. (2003) Understanding the Public Health Impacts of Farm Vehicle Public Road Crashes in North Carolina. Journal of Agricultural Safety and Health, 9, 19-32. https://doi.org/10.13031/2013.12347

[10] National Highway Traffic Safety Administration (2017) Traffic Safety Facts 2017. National Highway Traffic Safety Administration, Washington DC.

[11] Hanna, H.M., Schwab, C.V., Lehtola, C.J. and Steffen, R.W. (1997) Evaluation of Tractor and Grain Wagon Safety Marking at Selected Commercial Iowa Grain Elevators. Journal of Agricultural Safety and Health, 3, 91.

https://doi.org/10.13031/2013.17749

[12] Jaarsma, C.F. and de Vries, J.R. (2014) Agricultural Vehicles and Rural Road Safety: Tackling a Persistent Problem. Traffic Injury Prevention, 15, 94-101.

https://doi.org/10.1080/15389588.2013.789135

[13] Scott, E., Hirabayashi, L., Jones, N., Krupa, N. and Jenkins, P. (2019) Characteristics of Agriculture Related Motor Vehicle Crashes in Rural New York State. Journal of agromedicine, 25, 173-178. https://doi.org/10.1080/1059924X.2019.1623143

[14] Autoridade Nacional Seguranca Rodoviaria (ANSR) (2014) Ficha temática "Veículos agrícolas". http://www.ansr.pt/Estatisticas/FichasTematicas 
[15] Johansson, R. (2009) Vision Zero-Implementing a Policy for Traffic Safety. Safety Science, 47, 826-831. https://doi.org/10.1016/j.ssci.2008.10.023

[16] Ecola, L., Popper, S.W., Silberglitt, R. and Fraade-Blanar, L. (2018) The Road to Zero: A Vision for Achieving Zero Roadway Deaths by 2050. RAND Corporation, Santa Monica. http://www.rand.org/t/RR2333

[17] Volpe, J.A. (1971) Agricultural Tractor Safety on Public Roads and Farms: A Report to the Congress. Report No. 20402. United States Department of Transportation, Washington DC.

[18] Runyan, J.L. (1993) A Review of Farm Accident Data Sources and Research. US Department of Agriculture, Economic Research Service, Washington DC.

[19] Gerberich, S.G., Robertson, L.S., Gibson, R.W. and Renier, C.B.S. (1996) An Epidemiological Study of Roadway Fatalities Related to Farm Vehicles: United States, 1988 to 1993. Journal of Occupational \& Environmental Medicine, 38, 1135-1140. https://doi.org/10.1097/00043764-199611000-00013

[20] Peek-Asa, C., Sprince, N.L., Whitten, P.S., Falb, S.R., Madsen, M.D. and Zwerling, C. (2007) Characteristics of Crashes With Farm Equipment That Increase Potential for Injury. The Journal of Rural Health, 23, 339-347. https://doi.org/10.1111/j.1748-0361.2007.00112.x

[21] Zhang, X., Yang, Y., Chen, Y., Yao, H., Wu, M., Cui, M., et al. (2017) Road Traffic Crashes among Farm Vehicle Drivers in Southern China: A Cross-Sectional Survey. Traffic Injury Prevention, 18, 83-87. https://doi.org/10.1080/15389588.2016.1190840

[22] Lacy, J.K., Hunter, W. and Huang, H. (2003) Study of Farm Vehicle Crashes in North Carolina. Transportation Research Record: Journal of the Transportation Research Board, 1840, 178-185. https://doi.org/10.3141\%2F1840-20 https://journals.sagepub.com/doi/pdf/10.3141/1840-20

[23] National Highway Traffic Safety Administration (2018) FARS Encyclopedia. https://www-fars.nhtsa.dot.gov/Vehicles/VehiclesAllVehicles.aspx

[24] Karimi, K. and Faghri, A. (2021) Study of Farm Vehicle Crashes in Delaware. Delaware Center for Transportation, University of Delaware, Newark, Delaware, USA.

[25] Gkritza, K., Kinzenbaw, C.R., Hallmark, S. and Hawkins, N. (2010) An Empirical Analysis of Farm Vehicle Crash Injury Severities on Iowa's Public Road System. Accident: Analysis and Prevention, 42, 1392-1397. https://doi.org/10.1016/j.aap.2010.03.003

[26] Iowa Department of Transportation (2015) Spring Is Here-Share the Road with Farm Equipment.

https://www.transportationmatters.iowadot.gov/2015/04/spring-is-here-share-the-r oad-with-farm-equipment.html

[27] Hughes, R. and Rodgman, E. (2000) Crashes Involving Farm Tractors and Other Farm Vehicles/Equipment in North Carolina 1995-1999. University of North Carolina Highway Safety Research Center, Chapel Hill. https://rosap.ntl.bts.gov/view/dot/4790

[28] Pinzke, S., Nilsson, K. and Lundqvist, P. (2014) Farm Tractors on Swedish Public Roads-Age-Related Perspectives on Police Reported Incidents and Injuries. Work, 49, 39-49. https://doi.org/10.3233/WOR-131767

[29] Costello, T.M., Schulman, M.D. and Mitchell, R.E. (2005) Risk Factors for a Farm Vehicle Public Road Crash. Psychology, North Carolina State University, Raleigh. https://repository.lib.ncsu.edu/bitstream/handle/1840.16/3424/etd.pdf?sequence $=1$ 
[30] The National Institute for Occupational Safety and Health (NIOSH) (2020) Agricultural Safety. https://www.cdc.gov/niosh/topics/aginjury/default.html

[31] Houshyar, E. and Houshyar, M. (2018) Tractor Safety and Related Injuries in Iranian Farms. Safety Science, 103, 88-93. https://doi.org/10.1016/j.ssci.2017.11.018

[32] Myers, M.L., Cole, H.P. and Westneat, S.C. (2009) Injury Severity Related to Overturn Characteristics of Tractors. Journal of Safety Research, 40, 165-170. https://doi.org/10.1016/j.jsr.2009.02.007

[33] Abubakar, M., Ahmad, D. and Akande, F.B. (2010) A Review of Farm Tractor Overturning Accidents and Safety. Pertanika Journal of Science and Technology, 18, 377-385.

[34] Lehtola, C.J. (1992) An Investigation of Tractor-Related Farm Accidents in Iowa during 1988-1990. Retrospective Theses, Iowa State University, Ames. https://lib.dr.iastate.edu/rtd/10326

[35] Kuhn-usa.com (2021) KUHN Krause 4400 Packer-Superior Seedbed Preparation. https://www.kuhn-usa.com/crop/tillage-tools/packers/4400-packer

[36] Karsky, T. and Jaussi, A.K. (1998) Highway Transport of Agricultural Equipment: Preventing Public Road Accidents.

https://research.wsulibs.wsu.edu/xmlui/bitstream/handle/2376/7180/pnw512e.pdf?s equence $=1$ \&is Allowed $=\mathrm{y}$

[37] Murphy, D.J., Myers, J., McKenzie, E.A., Cavaletto, R., May, J. and Sorensen, J. (2010) Tractors and Rollover Protection in the United States. Journal of Agromedicine, 15, 249-263. https://doi.org/10.1080/1059924X.2010.484309

[38] Cole, H.P., Lehtola, C.J., Thomas, S.R. and Hadley, M. (2000) Facts about Tractor/Motor Vehicle Collisions. University of Florida, Department of Biological and Agricultural Engineering. https://nasdonline.org/static_content/documents/1010/TMVC\%20doc.pdf

[39] Cole, H.P., Piercy, L.R., Heinz, K.L., Westneat, S.C., Arrowsmith, H.E. and Raymond, K.M. (2009) Safety Status of Farm Tractors That Operate on Public Highways in Four Rural Kentucky Counties. Journal of Agricultural Safety and Health, 15, 207-223. https://doi.org/10.13031/2013.27406

[40] Quiros, L. and Shaver, B. (2003) Rural Road Links: A Review on Current Research Projects \& Initiatives Aimed at Reducing Vehicle Crash Fatalities on Rural Roads. University of California at Berkeley, Berkeley. https://escholarship.org/content/qt7280d52g/qt7280d52g.pdf

[41] American Association of State Highway and Transportation Officials (AASHTO) (2005) AASHTO Strategic Highway Safety Plan: A Comprehensive Plan to Substantially Reduce Vehicle-Related Fatalities and Injuries on the Nation's Highways. AASHTO, USA.

[42] National Highway Traffic Safety Administration (2019) Rural/Urban Comparison of Traffic Fatalities. DOT HS 812741, U.S. Department of Transportation, Washington DC. https://crashstats.nhtsa.dot.gov/

[43] Lord, D., Brewer, M.A., Fitzpatrick, K., Geedipally, S.R. and Peng, Y. (2011) Analysis of Roadway Departure Crashes on Two-Lane Rural Roads in Texas. http://tti.tamu.edu/documents/0-6031-1.pdf

[44] Deng, Z., Ivan, J.N. and Gårder, P. (2006) Analysis of Factors Affecting the Severity of Head-On Crashes. Transportation Research Record: Journal of the Transportation Research Board, 1953, 137-146. https://doi.org/10.1177\%2F0361198106195300116 
[45] Preston, H. and Schoenecker, T. (1999) Safety Impacts of Street Lighting at Isolated Rural Intersections. Brown Reynolds Watford Architects, Inc., Minneapolis. https://www.lrrb.org/pdf/199917.pdf

[46] Bonifas, C. (2020) Rural Connections: Challenges and Opportunities in America's Heartland. A National Transportation Research Nonprofit. National Transportation Research Nonprofit, Washington DC.

[47] Hughes, W.E. (1995) Investigation of Crashes with Animals. FHWA-RD-94-156, Federal Highway Administration, Research and Development, Turner-Fairbank Highway Research Center, McLean. https://www.fhwa.dot.gov/publications/research/safety/humanfac/94156.cfm

[48] Whitford, F. and Lester, D. (2011) Farm Truck Accidents: Considering Your Liability Management Options (PPP-91). Purdue University, West Lafayette.

[49] Luginbuhl, R.C., Jones, V.C. and Langley, R.L. (2003) Farmers' Perceptions and Concerns: The Risks of Driving Farm Vehicles on Rural Roadways in North Carolina. Journal of Agricultural Safety and Health, 9, 327-348.

https://www.researchgate.net/profile/Ricky_Langley/publication/8955444_Farmersa _Perceptions_and_Concerns_The_Risks_of_Driving_Farm_Vehicles_on_Rural_Ro adways_in_North_Carolina/links/561d63e408aecade1acb3bda.pdf https://doi.org/10.13031/2013.15461

[50] Finkel, E., McCormick, C., Mitman, M., Abel, S. and Clark, J. (2020) Integrating the Safe System Approach with the Highway Safety Improvement Program. Federal Highway Administration (FHWA), Washington DC. https://safety.fhwa.dot.gov/hsip/docs/fhwasa2018.pdf

[51] Jaarsma, C.F., Botma, H. and Beunen, R. (2005) Passing Bays for Slow Moving Vehicles on Rural Two-Lane Roads. Transport Reviews, 25, 491-509.

https://doi.org/10.1080/01441640500038805

[52] ASABE (American Society of Agricultural and Biological Engineers) (2019) ASABE Publishes Standards for Highway Marking of Ag Equipment. American Society of Agricultural and Biological Engineers, St. Joseph.

https://www.asabe.org/News-Detail/asabe-publishes-revised-standards-for-highway -marking-of-tractors

[53] Reynolds, S.J. and Groves, W. (2000) Effectiveness of Roll-Over Protective Structures in Reducing Farm Tractor Fatalities. American Journal of Preventive Medicine, 18, 63-69. https://doi.org/10.1016/S0749-3797(00)00142-2 